\title{
PENGARUH METODE KANGURU TERHADAP PENINGKATAN BERAT BADAN PADA BBLR
}

\section{THE EFFECT OF KANGAROO METHOD ON IMPROVEMENT BODY WEIGHT ON LOW BIRTH WEIGHT}

\author{
Yeni Riskawati ${ }^{1}$, Martono Tri Utomo ${ }^{2}$ Pudji Lestari ${ }^{2}$ \\ 'Program Studi Pendidikan Bidan Fakultas Kedokteran \\ Universitas Airlangga Surabaya \\ ${ }^{2}$ Departemen Ilmu Kesehatan Anak, Fakultas Kedokteran \\ Universitas Airlangga Surabaya \\ ${ }^{3}$ Departemen Ilmu Kesehatan Masyarakat, Fakultas Kedokteran \\ Universitas Airlangga Surabaya \\ Alamat koresponden: \\ Wonorejo Selatan Gang 3A No 70A Rungkut Surabaya \\ Email : yeniriskawati79@gmail.com
}

\begin{abstract}
Abstrak
Latar Belakang : Di Indonesia angka kematian neonatal sebesar 15 bayi per 1000 angka kelahiran menurut SDKI tahun 2017, dan di Jawa Timur khususnya Surabaya pada tahun 2018 kematian BBLR sebesar 50 per 1000 kelahiran hidup, sedangkan di RSU Haji kematian BBLR sebesar 12 bayi dalam 1 tahun. Perawatan metode kanguru merupakan cara yang paling efektif untuk memenuhi kebutuhan dasar BBLR. Bayi dengan Berat badan 1500-2500 gram baik karena prematuritas atau kecil masa kehamilan (KMK) akan kehilangan berat badan berkisar antara 10-15\% pada 7 hari kehidupannya (ANU,2016) maka dari itu untuk mengatasi masalah agar BBLR tidak kehilangan berat badan dengan pemberian perawatan metode kanguru 4 komponen bertujuan meningkatkan berat badan, menjaga suhu tubuh tetap stabil dan memudahkan pemberian ASI Metode: metode penelitian ini adalah Observasional analitik dengan rancang penelitian Kohort. Jumlah sample sebanyak 40 BBLR dengan tehnik pengambilan sample menggunakan Sequential Sampling dalam kurun waktu Agustus-Oktober 2019.Variabel bebas adalah perawatan metode kanguru yang diberikan sebanyak 1-2 kali dalam sehari dengan durasi lebih dari 120 menit. Variabel terikatnya adalah peningkatan berat badan yang dilakukan 3x pengukuran.Hasil: Hasil penelitian menggunakan uji paired T test menunjukkan adanya peningkatan berat badan yaitu 1) pengukuran pertama sebesar 31,82 gram selama 3 hari dengan $\mathrm{p}=0,037,2$ ) pengukuran ke dua mengalami peningkatan sebesar 227,15 selama 7 hari, dengan $\mathrm{p}=0,000,3$ ) pengukuran ke tiga sebesar 258,97 dengan $\mathrm{p}=0,000$. Kesimpulan : pada penelitian terdapat perbedaan yang signifikan antara perawatan metode kanguru terhadap peningkatan berat badan BBLR di Ruang NICU Rumah Sakit Haji Surabaya.
\end{abstract}

Kata kunci : metode kanguru dan BBLR

\begin{abstract}
Background: In Indonesia the Neonatal mortality rate was 15 infants per 1000 births and in Surabaya in 2018 LBW deaths were 50 per 1000 live births, while in Haji General Hospital the LBW deaths were 12 babies in 1 year. Kangaroo care was the most effective way to meet the basic needs of LBW. Babies with 1500-2500 grams body weight either due to prematurity or small pregnancy period will lose weight ranging from 10-15\% in 7 days of life. To overcome the problem Kangaroo care method4 component aims to promote weight loss, maintain body temperature remains stable and facilitate breastfeeding Methods: The method of this study was observational analytic with the design of the study cohort. Total sample of $40 \mathrm{LBW}$
\end{abstract}

e-ISSN 2656-7806 (C) 2020

Published by Universitas Airlangga .This is an Open Access (OA) article distributed under the terms of the Creative Commons Attribution Share-Alike 4.0 International License (https://creativecommons.org/licenses/by-sa/4.0/). DOI: 10.20473/imhsj.v4i3.2020.241-252 
with sampling techniques using Sequential Sampling in the period August-October period 2019. Variabel was free kangaroo care method given 1-2 times a day with a duration of more than 120 minutes. The dependent variable was increased in body weight carried out $3 x$ the measurement. Results: The results of the study using paired T test showed an increase in body weight, namely 1) the first measurement of 31.82 grams for 3 days with $p=0.037,2)$ the second measurement increased by 227.15 for 7 days, with $p=$ $0,000,3)$ the third measurement was 258.97 with $p=0,000$. The conclusion: of the studied, that there were a significant difference between the kangaroo method treatments for weight gain in LBW in the NICU Room Haji Hospital Surabaya.

Keywords : kangaroo method, $L B W$

\section{PENDAHULUAN}

Di Indonesia, tingginya angka kematian pada bayi dengan berat lahir rendah dalam satu bulan pertama kehidupannya pada tahun 2013-2018 sebesar 6,2 \% (Riskesdas,2018) tingginya angka kematian BBLR ini didukung oleh Laporan Survei Demografi dan Kesehatan Indonesia (SDKI) pada tahun 2017 menyebutkan bahwa kematian bayi di Indonesia sejumlah 24 per 1.000 kelahiran hidup,sedangkan kematian neonatal sejumlah 15 per 1.000 kelahiran hidup (SDKI, 2017).

Tingkat morbiditas dan mortalitas bayi dengan BBLR yang tinggi membuktikan kerentanan hidup pada periode ini, transisi kehidupan bayi dari intra uterine ke extra uterine memerlukan banyak perubahan biokimia dan fisiologis. Bayi dengan berat badan rendah cenderung mengalami komplikasi dan resiko infeksi, masalah-masalah yang ditemui pada BBLR ini berupa gangguan Metabolik seperti hipotermi, hipoglikemi, hiperglikemi, masalah pemberian ASI, gangguan imunitas, gangguan pernafasan, gangguan sistem peredaran darah, gangguan jantung, gangguan cairan elektrolit dan gangguan pencernaan. (Proverawati, 2014)

Berdasarkan masalah-masalah yang sering dijumpai diatas dapat diketahui bahwa BBLR mempunyai kebutuhan khusus diantaranya kebutuhan untuk mendapatkan suhu tubuh yang stabil, dan nutrisi yang cukup terutama ASI. Perawatan khusus yang dilakukan pada bayi BBLR selama ini adalah berupa perawatan dengan inkubator, penggunaan inkubator untuk merawat bayi berat lahir rendah (BBLR) memerlukan biaya tinggi dan tak jarang di Rumah Sakit satu inkubator ditempati lebih dari satu bayi dan menyebabkan meningkatnya resiko infeksi nosokomial pada bayi, sehingga dibutuhkan perawatan alternatif lainnya, yaitu dengan Perawatan Metode Kanguru (PMK) didefinisikan sebagai perawatan antara ibu dan bayi sejak dini, berkelanjutan dan 
berproses panjang dengan perawatan yang dilakukan kontak kulit ke kulit dengan menyusui secara ekslusif. Shabina A,dkk ( 2021)

Tujuan dari penelitian ini adalah menganalisa pengaruh perawatan metode kanguru terhadap peningkatan berat badan pada bayi BBLR di Ruang NICU RSU Haji Surabaya. Hipotesa penelitian "Ada pengaruh perawatan metode kanguru terhadap peningkatan berat badan pada BBLR di Ruang NICU RSU Haji Surabaya.”

\section{METODE}

Rancangan penelitian yang digunakan adalah Observasional Analitik design dengan metode pendekatan Kohort. Populasi pada penelitian ini adalah semua BBLR yang memenuhi syarat inklusi di Ruang NICU RSU Haji Surabaya, perkiraan jumlah sampel penelitian sebesar 36 responden. Pada pelaksaan penelitian, responden yang didapatkan sebesar 40 responden. Tehnik Sampel yang digunakan adalah Sequintal Sampling. Variabel bebas dalam penelitian ini adalah perawatan metode kanguru. Variabel terikat adalah peningkatan berat badan pada BBLR dengan kreteria inklusi bayi BBLR tanpa melihat usai gestasi dengan BB lahir antara 1200-<2500 gram, bayi tidak ada kelainan, vital sign dalam batas normal, reflek menelan baik, bayi bisa minum dengan ASI/SUFOR, dirawat minimal 10 hari hari diruang NICU, orang tua setuju menjadi responden, sedangkan kreteria ekslusi bayimemiliki kelainan, selama di inkubator perkembangan bayi tidak membaik. Perawatan metode kanguru berskala data rasio dan diukur dengan lembar pengumpul data, lembar observasi.

Pengumpulan data dilakukan pada bulan Agustus-Oktober 2019 dimulai dengan menentukan sampel penelitian. Sebelum dilakukan perawatan metode kanguru ibu dan keluarga yang lainnya dilakukan edukasi tentang cara melakukan perawatan metode kanguru kemudian dilakukan observasi penimbangan berat badan sebanyak 3 kali pada saat pertama kali masuk ruang NICU, bayi keluar Rumah Sakit dan post (hari ke 7) keluar dari Rumah sakit. Pengolahan data dilakukan dengan editing, entry, cleaning, dan tabulasi data. Data yang sudah terkumpul dan diolah dengan menggunakan uji $\mathrm{t}$ berpasangan (paired T test) dengan bantuan komputer SPSS. 


\section{HASIL DAN PEMBAHASAN}

\section{Peningkatan berat badan}

Penimbangan berat badan dilakukan dengan menggunakan uji t berpasangan (paired T test) sebanyak 3 kali yaitu pengukuran pertama dilakukan pada saat bayi masuk ke ruang NICU pertama kali, setelah kondisi bayi stabil maka akan direncanakan perawatan metode kanguru selama 3 hari jika kondisi bayi memenuhi syarat untuk keluar Rumah Sakit maka bayi akan dipulangkan dan timbang berat badan sewaktu KRS. Penimbangan yang ke tiga dilakukan setelah 7 hari keluar dari Rumah Sakit.

Tabel 1 Rata-rata berat badan pada pengujian ke 1,2 dan 3 pada kelompok PMK

\begin{tabular}{|c|c|c|c|c|c|}
\hline & Kelompok & $\begin{array}{c}\text { Mean } \\
\text { (gram) }\end{array}$ & SD & $\begin{array}{c}\text { Rata-rata } \\
\text { Defiasi }\end{array}$ & $\mathrm{P}$ value \\
\hline \multirow{2}{*}{$\begin{array}{l}\text { Penim- } \\
\text { bangan } 1\end{array}$} & BB di RS (gram) & 1880,15 & \multirow{2}{*}{93.45} & \multirow{2}{*}{31.82} & \multirow{2}{*}{0.037} \\
\hline & BB KRS (gram) & 1911,98 & & & \\
\hline \multirow{2}{*}{$\begin{array}{l}\text { Penim- } \\
\text { bangan } 2\end{array}$} & BB KRS (gram) & 1911,98 & \multirow{2}{*}{51.23} & \multirow{2}{*}{227.15} & \multirow{2}{*}{0.000} \\
\hline & BB Kontrol (gram) & 2139,13 & & & \\
\hline \multirow{2}{*}{$\begin{array}{l}\text { Penim- } \\
\text { bangan } 3\end{array}$} & BB di RS (gram) & 1880,15 & \multirow{2}{*}{127.00} & \multirow{2}{*}{258.97} & \multirow{2}{*}{0.000} \\
\hline & BB Kontrol (gram) & 2139,13 & & & \\
\hline
\end{tabular}


Grafik 1 Peningkatan BB antara di RS, KRS, dan kontrol

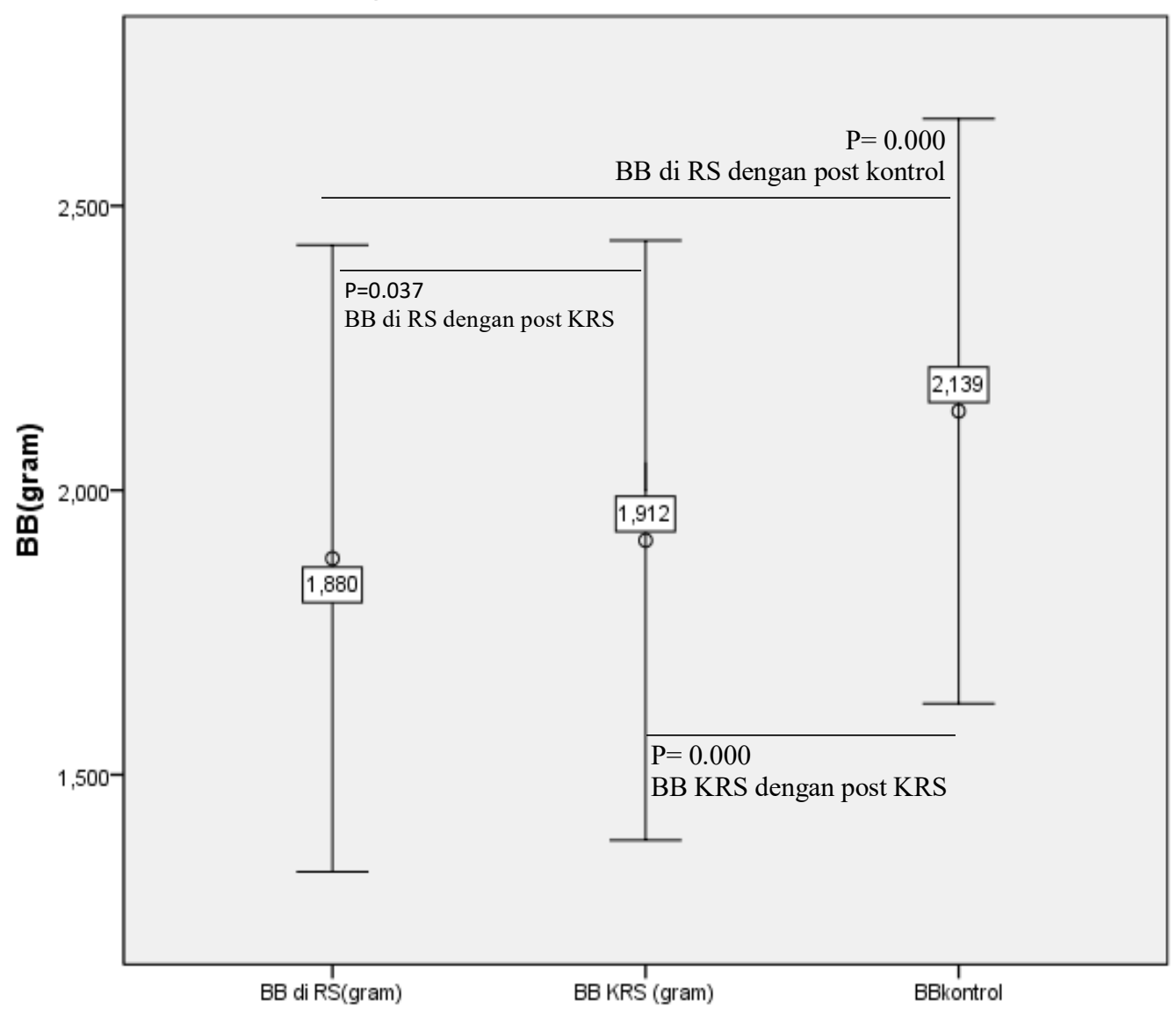

Tabel 1 dan grafik 1 Menunjukkan hasil peningkatan berat badan didapatkan penimbangan pertama $\mathrm{p}=0,037$, penimbangan ke dua didapatkan $\mathrm{p}=0,000$, penimbangan ke tiga didapatkan $\mathrm{p}=0,000$ yang menunjukkan adanya perbedaan peningkatan berat badan antara sebelum dan sesudah perawatan metode kanguru.

Hasil penelitian menggunakan uji Paired T Test menunjukkan adanya peningkatan berat badan yaitu 1) pengukuran pertama sebesar 31,82 gram selama 3 hari dengan $\mathrm{p}=$ $0,037,2)$ pengukuran ke dua mengalami peningkatan sebesar 227,15 selama 7 hari, dengan $\mathrm{p}=0,000,3$ ) pengukuran ke tiga sebesar 258,97 dengan $\mathrm{p}=0,000$. Secara fisiologis berat badan bayi akan mengalami penurunan $10 \%$ dibawah berat badan lahir pada minggu pertama (7 hari) yang disebabkan sekresi cairan ekstravaskuler yang berlebihan dan kemungkinan masukan makanan yang kurang. Bayi harus bertambah atau melebihi berat badan lagi pada saat berumur 2 minggu (10-14 hari) dan harus bertumbuh kira-kira 15-30 gram/ hari selama bulan pertama kehidupan (ANU,2016). Pemberian Perawatan metode kanguru sangat efektif karena sangat berpengaruh untuk peningkatan berat badan BBLR. Selain itu dengan kangaroo position ini menjadikan bayi lebih rilek, beristirahat dengan posisi yang menyenangkan mirip dengan posisi didalam rahim sehingga 
kegelisahan bayi berkurang dan tidur lebih lama. Pada keadaan demikian konsumsi oksigen dan kalori berada pada tingkat paling rendah, sehingga kalori yang ada akan digunakan untuk menaikkan berat badan (ANU,2016).

Hal ini terbukti dari hasil penelitian menunjukkan peningkatan berat badan pada pengukuran pertama yaitu peningkatan berat badan sewaktu di Rumah sakit dan akan keluar Rumah Sakit, besar selisih dalam kelompok adalah 31,82 gram setelah dilakukan PMK selama 3 hari dengan durasi lebih dari 120 menit sebanyak 1-2 kali dalam sehari, yang artinya berat badan bayi BBLR mengalami peningkatan sebesar 10,6 gram/hari. Pada pengukuran ke dua didapatkan ada peningkatan berat badan BBLR sebesar 227,15 gram setelah dilakukan PMK selama 7 hari dirumah dengan durasi lebih dari 120 menit sebanyak 2 kali dalam sehari, yang artinya ada peningkatan berat badan lebih besar dari sebelumnya yaitu 32,45 gram/hari. Peningkatan tersebut melebihi standar yang ditentuan oleh ANU (2016) yaitu 15-30 gram/hari .Berikut adalah grafik kenaikan berat badan setelah dilakukan PMK.

\section{Grafik 2 Peningkatan BB di RS, KRS, dan kontrol}

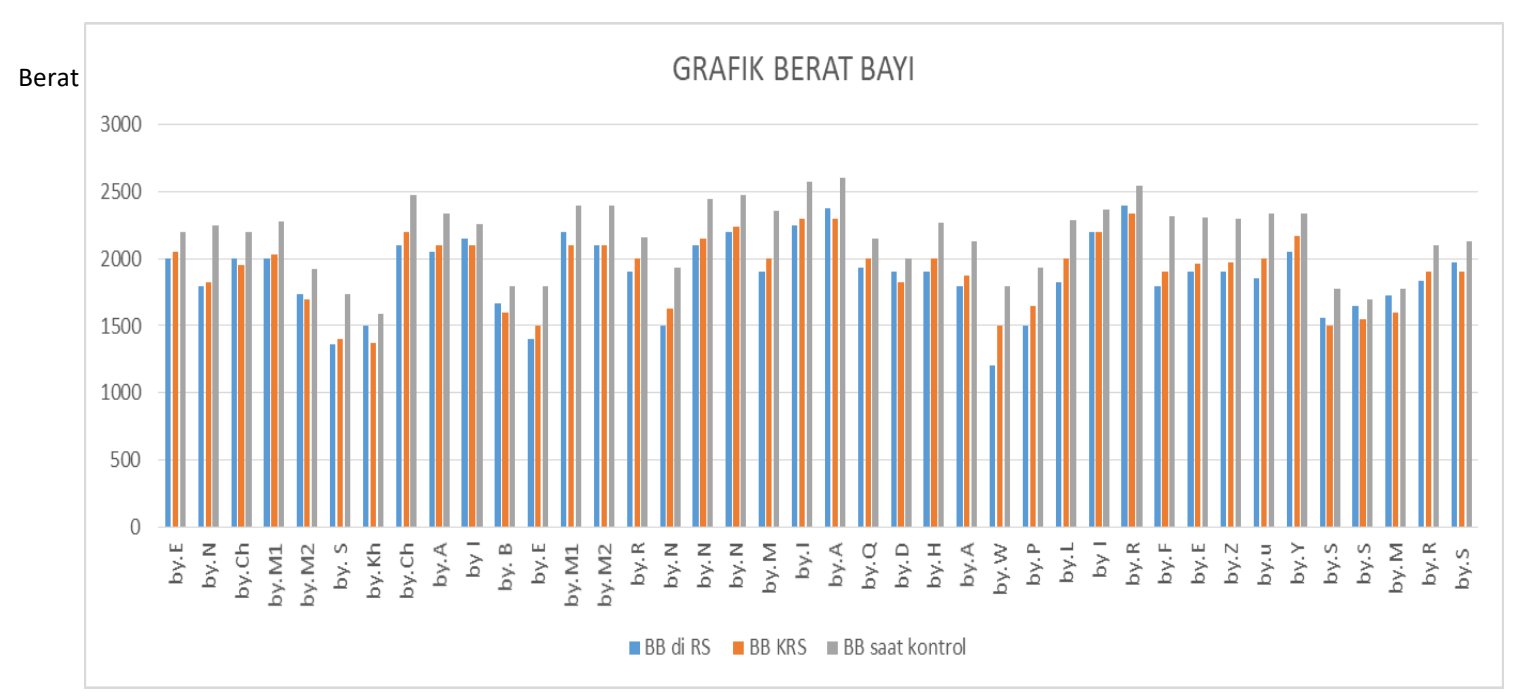

\section{Lama perawatan metode kanguru terhadap suhu tubuh}

Lama Perawatan Metode Kanguru terhadap suhu tubuh selama minimal 1,5 jam sampai dengan maksimal 3 jam diperoleh suhu tubuh minimal $36^{\circ} \mathrm{C}$ dan maksimal $37,4^{\circ} \mathrm{C}$. Sedangkan rata-rata suhu tubuh dari 40 responden diperoleh sebesar $36,7^{\circ} \mathrm{C}$.Berdasarkan hasil penelitian bahwa antara lama perawatan metode kanguru dengan peningkatan suhu tubuh tidak mengalami perubahan yang signifikan. 
Selain meningkatkan berat badan, PMK juga meningkatkan suhu tubuh dan melatih reflek hisap bayi baik itu preterm maupun bayi dengan kecil masa kehamilan (KMK). Pada penelitian ini menunjukkan hasil yang tidak signifikan yaitu lamanya perawatan metode kanguru tidak mempengaruhi peningkatan suhu tubuh akan tetapi suhu tubuh pada BBLR tetap stabil. Menurut Heni Heriyati (2018) menyatakan secara fisiologis bayi baru lahir akan kehilangan panas empat kali lebih besar dari pada orang dewasa, sehingga mengakibatkan terjadinya penurunan suhu tubuh, pada suhu ruang $20-25^{\circ} \mathrm{C}$ suhu kulit bayi sekitar $3-4{ }^{\circ} \mathrm{C}$. penurunan ini bisa disebabkan oleh kehilangan panas secara konduksi, konveksi, evaporasi dan radiasi. Pada BBLR jaringan lemak sub kutan lebih tipis sehingga lebih cepat kehilangan panas tubuh dan kemampuan BBLR yang belum sempurna dalam memproduksi panas maka BBLR akan semakin rentan mengalami penurunan panas tubuh. Perawatan BBLR di RSU Haji Surabaya berada dalam inkubator dengan suhu ruang inkubator yang perlahan-lahan diturunkan sesuai suhu ruangan. Perubahan suhu inkubator dan suhu ruang menyebabkan terjadi hipotermi pada BBLR, pemberian PMK dapat menstabilkan suhu tubuh bayi dengan frog position bayi berada didalam dekapan ibu, kulit bayi dan ibu saling menempel, kepala bayi dengan memakai topi berada diantara payudara ibu, kondisi suhu tubuh bayi ini menjaga tetap hangat (IDAI,2016). Selain itu perawatan metode kanguru pada bayi BBLR meningkatkan ikatan batin antar ibu terhadap bayi dan oksigenasi dalam pernafasan bayi sehingga mencegah terjadinya desaturasi dan apnoe. Melvina Evereklian ( 2017)

Hasil penelitian pelaksanaan perawatan metode kanguru terhadap peningkatan suhu tubuh terhadap BBLR sebanyak 40 responden, dapat dilihat pada tabel 2 dan grafik 3. 
Tabel 2 Lama perawatan metode kanguru terhadap peningkatan suhu tubuh

\begin{tabular}{lccc}
\hline Kategori & Minimal & Mean & Maximal \\
\hline Suhu tubuh & 36 & 36,7 & 37,4 \\
\hline
\end{tabular}

Grafik 3 Lama perawatan metode kanguru terhadap peningkatan suhu tubuh

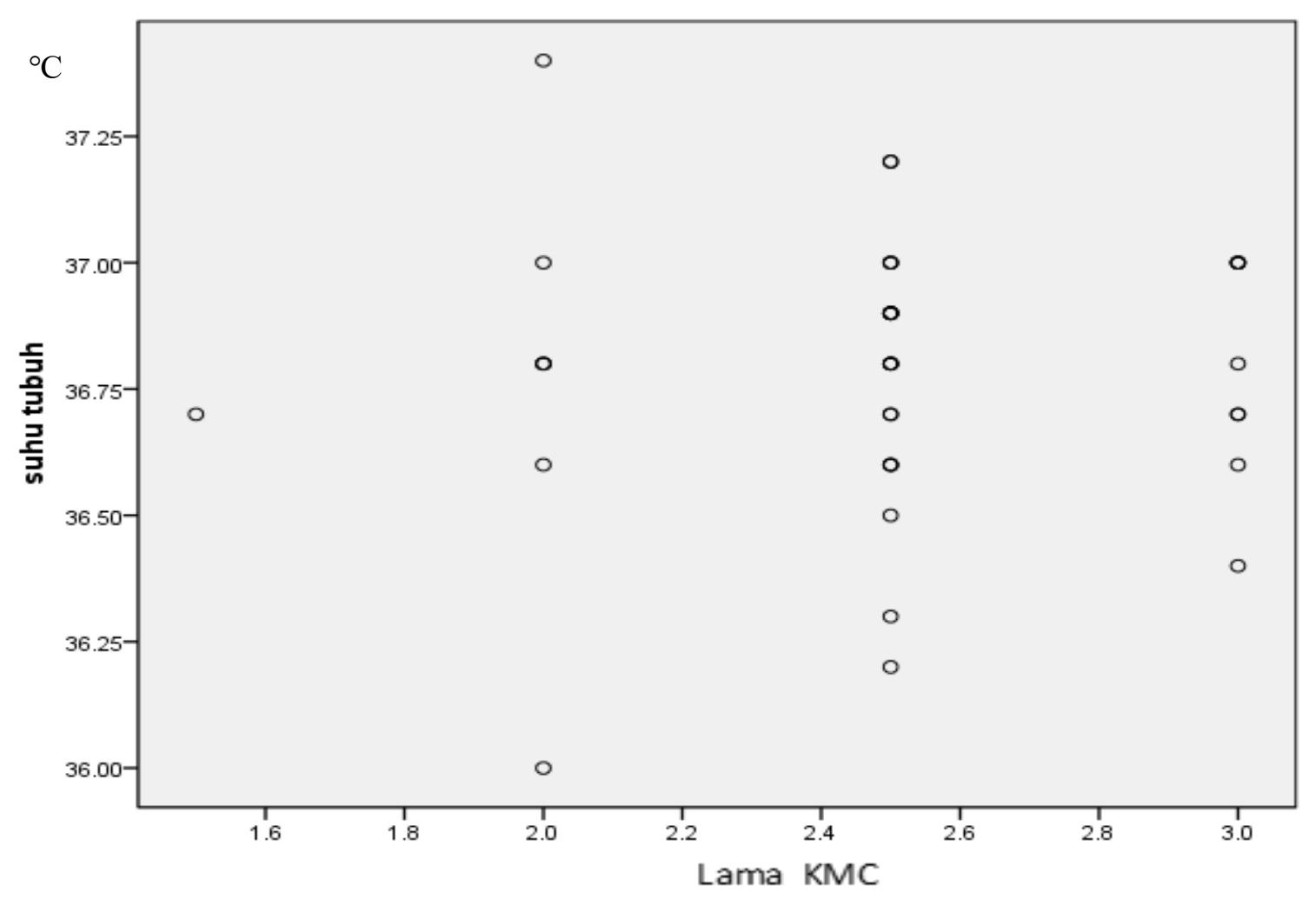

\section{Perawatan Metode Kanguru terhadap lama menyusu}

Lama menyusu bayi BBLR selama minimal 1,5 jam sampai dengan maksimal 3 jam diperoleh lama menyusu minimal 45 menit dan maksimal 90 menit. Sedangkan ratarata lama mnyusu dari 40 responden diperoleh sebesar 70.5 menit. Berdasarkan hasil penelitian bahwa antara lama perawatan metode kanguru dengan lama menyusu tidak mengalami perubahan yang signifikan. 
Tabel 3 Lama perawatan metode kanguru terhadap lama menyusu

\begin{tabular}{lccc}
\hline Kategori & Minimal & Mean & Maximal \\
\hline Lama menyusu & 45 & 70,5 & 90
\end{tabular}

\section{Grafik 4 Lama perawatan metode kanguru terhadap lama menyusu}

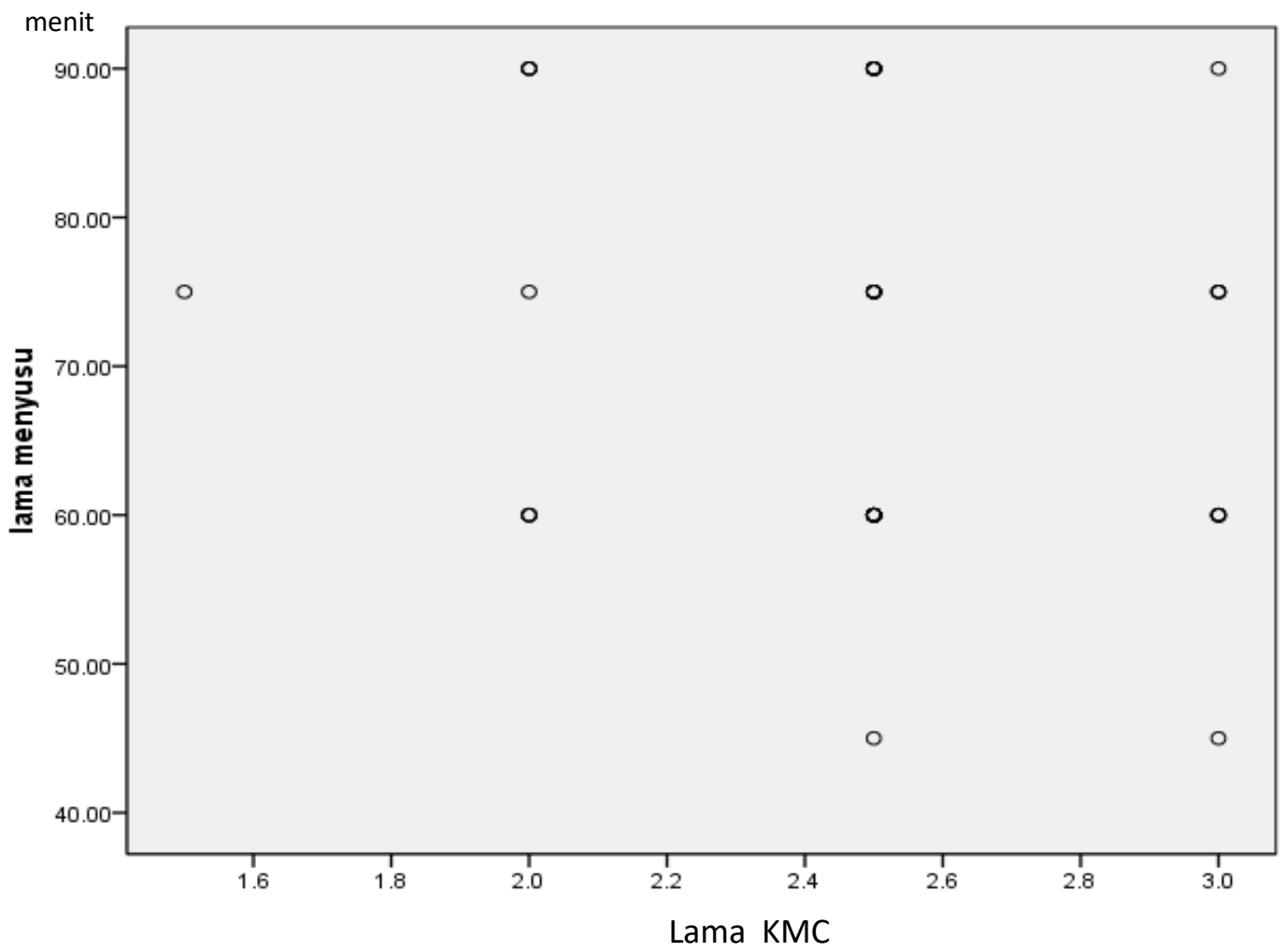

Pada bayi prematur dan IUGR cenderung mengalami masalah dalam reflek hisap dan menelan. Hasil penelitian pelaksanaan perawatan metode kanguru tidak signifikan yaitu lama Perawatan Metode Kanguru selama minimal 1,5 jam sampai dengan maksimal 3 jam diperoleh lama menyusu minimal 45 menit dan maksimal 90 menit. Sedangkan rata-rata lama menyusu dari 40 responden diperoleh sebesar 70.5 menit. Artinya antara waktu minimal dan waktu maksimal lama perawatan metode kanguru tidak berpengaruh terhadap lama menyusu bayi. Menurut penelitian Yuanita (2018) pada BBLR reflek hisap kurang kuat, reflek menelan belum ada, volume gaster sedikit, sering terjadi refluks dan peristaltik usus lambat, hal tersebut merupakan salah satu faktor kegagalan pemberian ASI, sehingga berat badan bayi tidak mengalami peningkatan.

BBLR dengan Kangaroo nutrition dalam perawatan metode kanguru bayi menempel pada puting dan menyusu kurang lebih 60-90 menit, waktu ini terbilang cukup lama akan tetapi proses menghisap bayi tidak kontinyu artinya bayi kadang menghisap 
kadang berhenti beberpa saat untuk istirahat karena pada bayi BBLR reflek menghisap dan menelan masih lemah. Dengan perawatan metode kanguru melatih reflek hisap dan menelan bayi BBLR menjadi lebih terlatih. Hal ini terjadi pada bayi dengan usia kehamilan preterm dengan berat badan kurang, pada bayi IUGR biasanya juga terjadi gangguan menghisap karena bayi IUGR biasanya BBLR dan usia kehamilan preterm. Selain melatih refllek hisap pada bayi prematur dengan menyusu dapat meningkatkan perkembangan kognitif dan motorik ,menurunkan insiden enterokolitis necrotikan yang menjadi salah satu penyebab kematian bayi prematur. Kristin P, dkk (2015). Keterlibatan orang tua dalam mengasuh BBLR sangat besar peranannya, dalam PERINASIA (2017) mengatakan bahwa keluarga memegang peranan penting dalam asuhan bayi baru lahir. Menurut Asri A(2021) bahwa edukasi yang memadai tentang skin-to-skin contact, feeding position, dan infant positioning oleh perawat akan menghasilkan kualitas metode kanguru yang sangat baik di kalangan ibu/orang tua/keluarga. kwalitas metode kanguru yang sangat baik dapat meningkatkan berat badan lebih cepat dan termostabilitas, menyebabkan rawat inap lebih pendek dan tingkat morbiditas yang lebih rendah di antara bayi BBLR. Secara keseluruhan metode kanguru yang diterapkan pada bayi BBLR dengan memenuhi syarat dapat meningkatkan pemberian ASI,keberhasilan menyusui dan meningkatkan stabilitas emosional sehingga memainkan peran integral dalam menurunkan mortalitas dan morbiditas.

Perawatan dengan melibatkan orang tua atau keluarga minimal diberikan 6 minggu pertama dalam kehidupan bayi baru lahir, strategi dan kebijakan dalam rawat inap sangat diperlukan dalam pertumbuhan dan perkembangan bayi terutama pada bayi prematur.Raouth R,Susan M (2019). Peran suami atau keluarga lain dalam mendukung ibu merawat bayi dengan metode kanguru adalah melakukan perawatan metode kanguru secara bergantian dengan anggota keluarga yang lain, menjaga ibu dari kelelahan yang berlebihan, menciptakan suasana yang hangat dan menyenangkan selama proses perawatan metode kanguru, hal tersebut akan sangat membantu ibu dalam menjalankan perannya sebagai ibu sehingga perawatan metode kanguru dapat dilakukan dengan baik. Sedangkan peran dari petugas kesehatan adalah memberikan edukasi tentang perawatan metode kanguru, peminjaman selendang metode kanguru selama di Rumah Sakit dan pendampingan pada proses perawatan metode kanguru selama dirumah sambil memberikan edukasi agar ibu termotivasi untuk rutin melakukan perawatan metode 
kanguru selama dirumah sampai BB bayi 2500 gram. Hal tersebut diatas akan membantu keberhasilan PMK baik diRumah sakit maupun di Rumah.

\section{KESIMPULAN DAN SARAN}

Dapat disimpulkan bahwa terdapat pengaruh dari perawatan metode kanguru terhadap peningkatan berat badan pada BBLR di Ruang NICU RSU Haji Surabaya, secara teori perawatan metode kanguru mempunyai 4 komponen yang saling berkaitan untuk menjaga bayi tetap sehat dan tumbuh dengan baik serta mencegah terjadinya peningkatan kematian pada BBLR khususnya karena prematuritas, kegunaan perawatan metode kanguru dengan 4 komponen adalah menjaga suhu tubuh tetap hangat, melatih reflek menghisap bayi menjadi lebih baik sehingga asupan nutrisi dapat terpenuhi dan berat badan meningkat secara signifikan yang tentunya tidak lepas dari peran ibu dan keluarga yang saling support dalam merawat bayi selama diRumah Sakit sampai dirumah. Dengan PMK yang tidak memerlukan biaya banyak dalam pelaksanaanya semoga bisa menjadi protap tetap di setiap Rumah Sakit dan dilakukan oleh para Ibu dengan BBLR dirumah sampai berat badan bayi mencapai 2500 gram.

\section{DAFTAR PUSTAKA}

Annual Neonatology Update. (2016), Workshop Manajemen BBLR level 3 Batu Malang. Asri Adisasmita,Yulia Izati,Septyana Choirunnisa,Hadi Pratomo,Luzy Adiyanti. (2021), Kangaroo Mother Care Knowledge, attitude and Pactice,Among Nursing Staff In Hospital In Jakarta. PubMed gov, https://doi.org/10.1371/journal.pone.0252704

Heni Heriyeni. (2018), Pengaruh Metode Kanguru terhadap Stabilitas Suhu Tubuh Bayi di Ruang Perinatologi RSUD Bengkalis, vol XII, no.10 Oktober 2018.

Konsensus Asuhan Nutrisi pada Bayi Prematur, IDAI, (2016)

Kristin P Tully,Diane Holditch-Davis,Rosemary C White-Traut,Richard David, T.Michael O’Shea,Victoria Geraldo.(2015),A Test Of Kangaroo Care On Preterm Infant Breastfeding,PubMed gov, https://doi.org/10.1016/j.jogn.2015.10.004

Melvina Evereklian,Bobbie Posmontier. (2017), The Impacy Of Kangaroo Care On Premature Infant Weight Gain,PubMed gov, https://doi.org/10.1016/j.pedn.2017.02.006

Perinasia. (2017). Program Manajemen Laktasi, Jakarta, Bina Rupa Aksara.

Proverawati, Atikah, Ismawati, Cahyo. (2014), BBLR Berat Badan Lahir Rendah, Yogyakarta : Nuha Medika, pp. 12-13.

Riset Kesehatan Dasar (Riskesdas). (2018) Badan Penelitian dan Pengembangan Kesehatan Kementrian RI tahun 2018. http://www.depkes.go.id./resources/download/infoterkini/materi rakorpop2018/hasil \%20Riskesdas\%202018.pdf-Diakes Agustus 2018. 
Raouth R.Kostandy, Susan M.Ludington-Hoe. (2019), The Evolution Of The Science Of Kangaroo ( Mother) Care ( Skin-To-Skin Contact),PubMed gov, https://doi.org/10.1002/bdr2.1565

SDKI. (2017). Survei Demogravi dan Kesehatan Indonesia. Jakarta.

Shabina Ariff, dkk.(2021), Effect Of Based Kangaroo Mother Care Package On Neonatal Mortality Among Preterm And Low Brithwieght Infant In Rural Pakistan : Protocol For a Cluster Randomized Controlled Trial. JMIR Publication, https://doi.org/10.2196/28156

Yuanita syaiful, Mukhlishotin. (2018). Perawatan Metode Kanguru Meningkatkan Keberhasiln Pemberian ASI pada BBLR,dari http://doi:10.5281/zenodo.1402279 